\title{
ARTICLE OPEN Atomic-scale structural signature of dynamic heterogeneities in metallic liquids
}

\author{
Alain Pasturel ${ }^{1}$ and Noel Jakse ${ }^{1}$
}

With sufficiently high cooling rates, liquids will cross their equilibrium melting temperatures and can be maintained in a metastable undercooled state before solidifying. Studies of undercooled liquids reveal several intriguing dynamic phenomena and because explicit connections between liquid structure and liquids dynamics are difficult to identify, it remains a major challenge to capture the underlying structural link to these phenomena. Ab initio molecular dynamics (AIMD) simulations are yet especially powerful in providing atomic-scale details otherwise not accessible in experiments. Through the AIMD-based study of $\mathrm{Cr}$ additions in Al-based liquids, we evidence for the first time a close relationship between the decoupling of component diffusion and the emergence of dynamic heterogeneities in the undercooling regime. In addition, we demonstrate that the origin of both phenomena is related to a structural heterogeneity caused by a strong interplay between chemical short-range order (CSRO) and local fivefold topology (ISRO) at the short-range scale in the liquid phase that develops into an icosahedral-based medium-range order (IMRO) upon undercooling. Finally, our findings reveal that this structural signature is also captured in the temperature dependence of partial pair-distribution functions which opens up the route to more elaborated experimental studies.

npj Computational Materials (2017)3:33 ; doi:10.1038/s41524-017-0034-y

\section{INTRODUCTION}

The nature of local structure in a liquid and its connection with its dynamic properties play a key role in understanding transformation pathways. On cooling, a liquid usually undergoes a first-order transition to form a crystal. However, it is also possible to form a metastable undercooled state by using cooling rates fast enough to avoid crystallization. On further cooling, a liquid becomes progressively more viscous and the dynamics changes significantly, exhibiting several intriguing dynamic phenomena such as (i) the Arrhenius-to-non-Arrhenius transition of transport quantities, i.e., diffusivity $\left(D_{s}\right)$, viscosity $(\eta)$ and structural relaxation time $(\tau){ }_{1}^{1-5}$ (ii) the occurrence of dynamic heterogeneities $(\mathrm{DHs})^{6-9}$ (iii) the breakdown of the Stokes-Einstein (SE) relation..$^{6,-15}$ So far, many studies have been devoted for understanding the physics underneath although it remains a major challenge to characterize order in disorder and to establish structure-dynamics relations.

For instance, the increase in the rate of viscosity with falling temperature down in the deep undercooling regime has been used by Angell ${ }^{1}$ to classify liquids by introducing the concept of fragility. Fragility has been related to thermodynamic properties, including the excess entropy and specific heat, ${ }^{16-18}$ suggesting that it should have a structural signature. Only recently, an empirical correlation between fragility and liquid structure has been proposed. 5

It has been also established that the kinetic slowing down in the undercooling regime accompanies the emergence of $\mathrm{DHs}^{6-9}$ However, in the same time, the static structure factor or the radial distribution function shows little change upon cooling, which apparently indicates the absence of a mesoscopic structure or order and seemingly suggests no essential change in liquid structure. Interestingly, DHs are a universal feature of undercooled liquids since they have been observed for strong as well as fragile liquids. ${ }^{6,} 9$

To circumvent difficulties to elucidate direct connections between liquid structure and liquid dynamics, relationships between dynamic phenomena have been extensively studied, especially the breakdown of SE relation in connection to DHs. In some studies, ${ }^{9}$ the presence of $\mathrm{DHs}$ has been argued to give rise to the decoupling of the self-diffusion $\left(D_{S}\right)$ and viscosity and then to the breakdown of SE relation, $D_{S} \eta / T=$ cste. Specifically, the breakdown of the SE relation has been related to the particles in fast regions while particles in slow regions obey the SE relation. ${ }^{14}$ However, some other studies proposed that it is not necessary to invoke DHs to explain the breakdown of SE relation ${ }^{13,19,20}$ and also evidenced that particles in both fast and slow regions can deviate from the SE relation. ${ }^{13,21}$

Therefore, despite intensive efforts, the physical factors that control these dynamic phenomena in the undercooling regime remain elusive.

More recently, the decoupling of component diffusion, so-called component decoupling, has been pointed out in the stable liquid phase of some metallic liquids, giving rise to an unexpected behavior in stable liquids. ${ }^{22,} 23$ Indeed, in a liquid at high temperatures, the diffusion process is governed by uncorrelated binary atomic collisions and the diffusivities of the different components of the system should be essentially equal. However, in a glass-forming Zr-based alloy, Basuki et al. ${ }^{22}$ found that diffusivities and viscosity follow an Arrhenius-type law but a factor of 2 between $\mathrm{Zr}$ diffusion and the diffusion of smaller components like $\mathrm{Co}$ or $\mathrm{Ni}$ exists at high temperatures and becomes as large as four at the liquidus temperature. In liquid $\mathrm{Al}-\mathrm{Zn}-\mathrm{Cr}$ alloys, ${ }^{23}$ a component decoupling has been also observed with a factor 3 between $\mathrm{Zn}$ and $\mathrm{Cr}$ diffusion at the liquidus temperature.

University Grenoble Alpes, CNRS, Grenoble INP, SIMaP, F-38000 Grenoble, France
Correspondence: Noel Jakse (noel.jakse@grenoble-inp.fr)

Received: 28 April 2017 Revised: 3 July 2017 Accepted: 12 July 2017 Published online: 17 August 2017 
As mentioned by Ediger et al. ${ }^{6}$ in glass-forming mixtures, the intrinsic properties of each component may impose their own heterogeneity. Within this scheme, the structural origin of component decoupling can be established in relation to the different local ordering around each component. Moreover, we can also imagine that the same structural mechanism may initiate the emergence of $\mathrm{DHs}$ in the undercooled regime.

Using the potential energy landscape (PEL) picture, ${ }^{2}$ this would mean that some liquids have a wider landscape-influenced region, which can affect their dynamic properties far above their liquidus temperatures. In fact, such an argument has been used by Basuki et $\mathrm{al}^{22}$ to interpret the decoupling of $\mathrm{Zr}$ diffusion in the liquid phase of the glass-forming $\mathrm{Zr}$ based alloy as a reflection of the formation of slow regions made up by $\mathrm{Zr}$ atoms in the undercooled regime. This interpretation is related to the strong character of this alloy, according to Angell's definition, as the landscape of a strong liquid may possess a single "mega-basin" leading to a weakly gradual structural ordering upon undercooling. $^{2}$

More striking is then the component decoupling in liquid Albased alloys due to $\mathrm{Cr}$ additions since these alloys are known to present a fragile character. For such alloys, the PEL is characterized by a proliferation of well-separated "mega-basins", which may cause a rapid evolution of local ordering during undercooling. ${ }^{2}$

Therefore, elucidating the relationship between the component decoupling and the emergence of $\mathrm{DHs}$ and revealing the underlying structural signature in relation to fragility may provide new insights into the origin of these phenomena.

In this study, we aim to quantify the correlation between the component decoupling and the emergence of $\mathrm{DHs}$ in fragile liquids by first exploring the temperature dependence of transport coefficients (e.g., self-diffusion constants, relation times and viscosity) in relation to $\mathrm{Cr}$ additions in liquid Al-based alloys. This is done through ab initio molecular dynamic (AIMD) simulations on two liquid alloys, e.g., $\mathrm{Al}_{93} \mathrm{Cr}_{7}$ and $\mathrm{Al}_{83} \mathrm{Zn}_{10} \mathrm{Cr}_{7}$. The $\mathrm{Cr}$ composition is chosen to get meaningful statistics while it preserves its minority character. This work extends our preceding study on $\mathrm{Al}_{93} \mathrm{Cr}_{7}{ }^{24}$

We find a strong decoupling of $\mathrm{Cr}$ diffusion from the diffusion of $\mathrm{Al}$ and from the $\mathrm{Al}$ and $\mathrm{Zn}$ diffusion in the liquid phases of $\mathrm{Al}_{93} \mathrm{Cr}_{7}$ and $\mathrm{Al}_{83} \mathrm{Zn}_{10} \mathrm{Cr}_{7}$, respectively. Below their experimental liquidus temperatures, we observe an acceleration of this decoupling, as well as the Arrhenius-to-non Arrhenius crossover of all investigated transport quantities. This crossover temperature corresponds also to the emergence of $\mathrm{DHs}$ for all the components but the SE relation is found to fail only for $\mathrm{Al}$ and $\mathrm{Zn}$ components.

Then, by investigating the evolution of local ordering during cooling, we demonstrate that the structural origin of the component decoupling in these alloys relies on a strong interplay between chemical short-range order (CSRO) and local fivefold topology (ISRO) leading to different local ordering around each component in the liquid phase of both alloys. Below the crossover temperature, this interplay induces the development of an icosahedral-based medium-range order (IMRO) referring to $\mathrm{Cr}$ atoms. In addition, the development of this IMRO yields an atomic-scale heterogeneity because IMRO has more $\mathrm{Cr}$ atoms than expected form the respective alloy composition.

Interestingly, our findings clearly indicate that the development of IMRO is captured by the temperature dependence of the $\mathrm{Cr}-\mathrm{Cr}$ pair-distribution function.

Finally, we show that a connection exits between IMRO and the structural basis of $\mathrm{DH}$ s using the isoconfigurational ensemble. ${ }^{8,25}$ In particular, we find the formation of fast regions made up by only $\mathrm{Al}$ atoms in $\mathrm{Al}_{93} \mathrm{Cr}_{7}$ or $\mathrm{Al}$ and $\mathrm{Zn}$ atoms in $\mathrm{Al}_{83} \mathrm{Zn}_{10} \mathrm{Cr}_{7}$ and slow regions enriched in $\mathrm{Cr}$ atoms with respect to the nominal composition of investigated alloys in phase with the chemically induced atomic-scale heterogeneity found in IMRO.

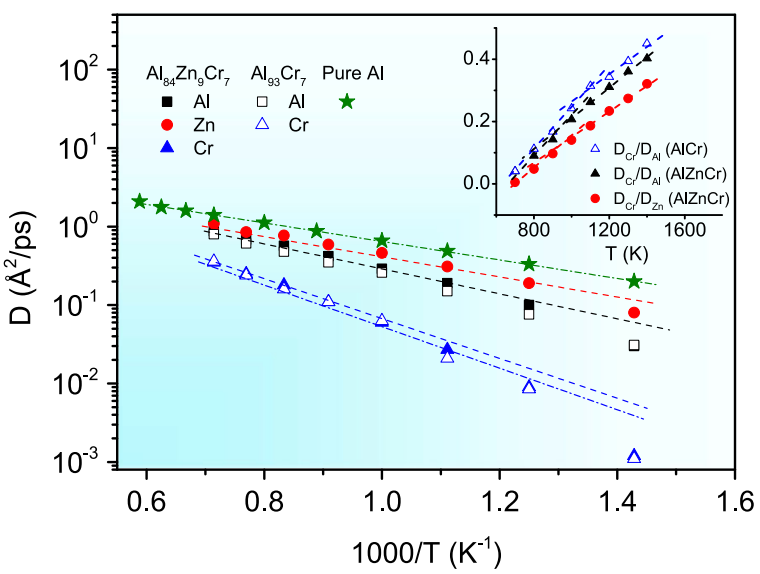

Fig. 1 Arrhenius plot of $\mathrm{Al}$ and $\mathrm{Zn}$ self-diffusion coefficients for the $\mathrm{Al}-\mathrm{Cr}$ binary alloy as well as $\mathrm{Al}, \mathrm{Zn}$, and $\mathrm{Cr}$ self-diffusion coefficients for the $\mathrm{Al}-\mathrm{Zn}-\mathrm{Cr}$ ternary alloy. The simulation data for pure liquid $\mathrm{Al}$ is also included for comparison. Dashed lines are the corresponding Arrhenius fit in the high-temperature range. The inset shows the temperature evolution of the ratio of the self-diffusion coefficients $D_{\mathrm{Cr}} / D_{\mathrm{Al}}$ in the Al-Cr binary alloy as well as the $D_{\mathrm{Cr}} / D_{\mathrm{Al}}$ and $D_{\mathrm{Cr}} / D_{\mathrm{Zn}}$ in the $\mathrm{Al}-\mathrm{Zn}-\mathrm{Cr}$ ternary alloy

\section{RESULTS}

Diffusivity

We have first evaluated self-diffusion coefficients in $\mathrm{Al}_{93} \mathrm{Cr}_{7}$ and $\mathrm{Al}_{83} \mathrm{Zn}_{10} \mathrm{Cr}_{7}$ liquids from the long time slope of the mean-square displacement (shown in Supplementary Figs. 1 and 2). Calculated self-diffusion $D_{i}$ for each $i$ component as a function of the inverse temperature are presented in Fig. 1 for both alloys. We have also plotted the self-diffusion coefficient of pure Al liquid.

Note that the temperature dependence of $D_{\mathrm{Al}}$ and $D_{\mathrm{Zn}}$ in the liquid $\mathrm{Al}_{90} \mathrm{Zn}_{10}$ alloy have been already investigated. ${ }^{26}$ We have shown that they display an Arrhenius-type law up to $700 \mathrm{~K}$ and their values are close to those of $D_{A l}$ in pure Al liquid. Such a result indicates that alloying effects between $\mathrm{Al}$ and $\mathrm{Zn}$ species in the liquid phase are rather small. ${ }^{27}$

From Fig. 1, it can be seen that the addition of $\mathrm{Cr}$ reduces significantly $D_{\mathrm{Al}}$ in $\mathrm{Al}_{93} \mathrm{Cr}_{7}$ and $D_{\mathrm{Zn}}$ and $D_{\mathrm{Al}}$ in $\mathrm{Al}_{83} \mathrm{Zn}_{10} \mathrm{Cr}_{7}$, making their motion more sluggish. In addition their inverse temperature dependence displays an Arrhenius-type behavior only at high temperatures while we detect a sharp deviation from the Arrhenius fit below a crossover temperature $T_{X}$ to be about 1000 and $900 \mathrm{~K}$ for $\mathrm{Al}_{93} \mathrm{Cr}_{7}$ and $\mathrm{Al}_{83} \mathrm{Zn}_{10} \mathrm{Cr}_{7}$ respectively, which are close to the liquidus temperature of both alloys. This is often attributed to either the increasingly cooperative dynamic processes or the emergence of various rearranging domains, in which atomic motion and relaxation times can differ significantly from one region to another. ${ }^{9}$

Interestingly, the $D_{\mathrm{Cr}} / D_{\mathrm{Al}}$ ratio in $\mathrm{Al}_{93} \mathrm{Cr}_{7}$ and $D_{\mathrm{Cr}} / D_{\mathrm{Zn}}$ and $D_{\mathrm{Cr}} / D_{\mathrm{Al}}$ ratios in $\mathrm{Al}_{83} \mathrm{Zn}_{10} \mathrm{Cr}_{7}$ shown in the inset of Fig. 1 emphasize that $\mathrm{Cr}$ dynamics is strongly decoupled from other components in both alloys and this decoupling is accelerated below $T_{x}$. We will see below how this decoupling of dynamics can be related to the emergence of DHs in these alloys. Finally, we mention that the value of $D_{\mathrm{Cr}} / D_{\mathrm{Zn}}$ at $T_{x}$ is in good agreement with the experimental result. $^{23}$

\section{Structural relaxation}

Next we analyzed the temperature dependence of the structural relaxation time $\tau_{\alpha}^{i}$ of $i$ component derived from the selfintermediate scattering function (SIS) shown in Supplementary Figs. 3 and 4. Figure 2 shows the temperature dependent behavior of $\tau_{a}^{i}$ in two metallic alloys as well as for pure Al liquid. At high 


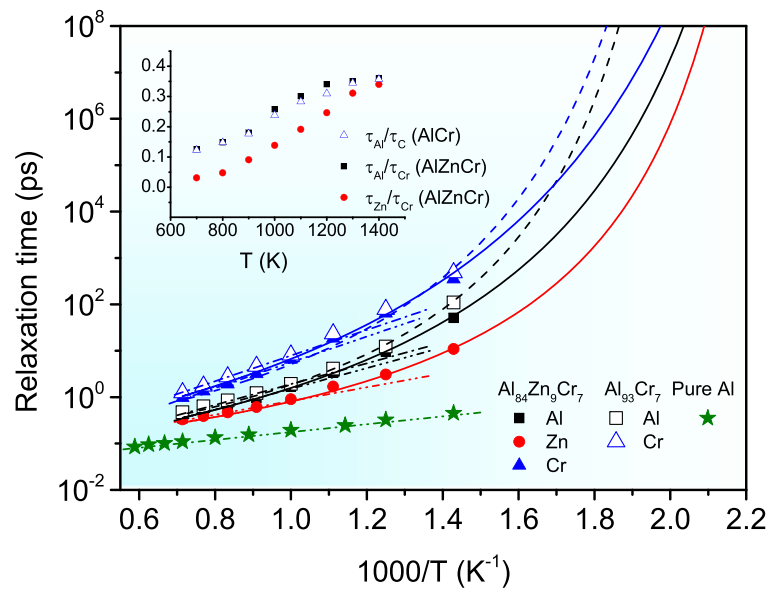

Fig. 2 Arrhenius plot of the $\alpha$-structural relaxation time of $\mathrm{Al}$ and $\mathrm{Cr}$ atoms for $\mathrm{Al}-\mathrm{Cr}$ binary alloy and $\mathrm{Al}, \mathrm{Zn}$, and $\mathrm{Cr}$ atoms for $\mathrm{Al}-\mathrm{Zn}-\mathrm{Cr}$ ternary alloy. The simulation data for pure liquid $\mathrm{Al}$ is also included for comparison. The dashed and solid lines correspond to the VFT fit of the $\alpha$-structural for $\mathrm{Al}-\mathrm{Cr}$ binary alloy and $\mathrm{Al}-\mathrm{Zn}-\mathrm{Cr}$ ternary alloy, respectively. Arrhenius fits in the temperature range $1400-1000 \mathrm{~K}$ for $\mathrm{Al}-\mathrm{Cr}$ (dashed-dotted lines) and $\mathrm{Al}-\mathrm{Zn}-\mathrm{Cr}$ (dashed-double-dotted lines)

temperatures, $\tau_{\alpha}^{i}$ changes almost linearly with $1 / T$, indicating an Arrhenius behavior, but increases drastically and deviates from the linear behavior in the undercooling regime of two alloys, i.e., below their respective values of $T_{x}$. However, we emphasize that the increase of $\tau_{a}^{C r}$ and $\tau_{a}^{A l}$ in the deep undercooling region is roughly similar in both alloys. We also report a significant decoupling in both alloys as for self-diffusion coefficients. If the $\tau_{a}^{A l} / \tau_{a}^{C r}$ ratio in $\mathrm{Al}_{93} \mathrm{Cr}_{7}$ and $\mathrm{Al}_{83} \mathrm{Zn}_{10} \mathrm{Cr}_{7}$ gives evidence of a much larger alpha-relaxation time for the heavy $\mathrm{Cr}$ atoms as expected, the value of $\tau_{a}^{Z n} / \tau_{a}^{C r}$ ratio in $\mathrm{Al}_{83} \mathrm{Zn}_{10} \mathrm{Cr}_{7}$ indicates that it is not the case.

The behavior of $\tau_{a}^{i}$ can be well described by the Arrhenius fit, $\tau_{\alpha}^{i}=\tau_{\infty}^{i} \exp \left(E_{i} / k_{B} T\right)$, in the high-temperature regime and by the Vogel-Fulcher-Tammann (VFT) equation, $\tau_{a}^{i}=\tau_{0}^{i} \exp \left[B_{i} /\left(T-T_{0}^{i}\right)\right]$, in the undercooling regime. Here, $k_{B}$ is Boltzmann constant and $T_{0}^{i}$ is the temperature at which the relation time of $i$ component becomes infinite. $\tau_{\infty}^{i}, E^{i}, \tau_{0}^{i}$, and $B_{i}$ are fitting parameters. To perform the VFT fit of our ab initio results, we used in addition the conventional value of $\tau_{a}^{i}=100 \mathrm{~s}$ at the glass transition temperature, i.e., $T_{G}$. $T_{G}$ is determined from the relation $T_{X} \cong 2 T_{\mathrm{G}}$ proposed by Jaiswal et al. ${ }^{28}$ on the basis of a large set of experimental data of various glass-forming liquids. As shown in Fig. 2, the VTF fit correlates well with the ab initio data for each relaxation time $\tau_{\alpha}^{i}$ in both alloys even in the hightemperature regime. In $\mathrm{Al}_{93} \mathrm{Cr}_{7}$, we obtain similar values of $B$ and $T_{0}$ for the two components, namely 3.50 and $456 \mathrm{~K}$ for Al and 3.53 and $457 \mathrm{~K}$ for $\mathrm{Cr}$. In $\mathrm{Al}_{93} \mathrm{Zn}_{10} \mathrm{Cr}_{7}$, we find the same trend with fitting values of $B$ and $T_{0}$ equal to 3.33 and $411 \mathrm{~K}, 3.42$ and $411 \mathrm{~K}$, 3.37 and $412 \mathrm{~K}$ for $\mathrm{Al}, \mathrm{Zn}$, and $\mathrm{Cr}$, respectively.

Then, we can infer the fragility parameter ${ }^{1}$ from the determination of $B, T_{0}$, and $T_{\mathrm{G}}$ using $m=B T_{0} T_{G} /\left[\left(T_{\mathrm{G}}-T_{0}\right)^{2}\right]$ in both alloys. We find similar values of the fragility parameter $\mathrm{m}$, e.g., 180 and 187 for $\mathrm{Al}$ and $\mathrm{Cr}$ in $\mathrm{Al}_{93} \mathrm{Cr}_{7}$ and 175,180 , and 187 for $\mathrm{Al}, \mathrm{Zn}$, and $\mathrm{Cr}$ in $\mathrm{Al}_{83} \mathrm{Zn}_{10} \mathrm{Cr}_{7}$.

\section{Viscosity}

We also determined viscosity using direct techniques based on the transverse current-current correlation function. ${ }^{29}$ The inverse temperature dependence of viscosity is shown in Fig. 3 for both liquid alloys, as well as for pure $\mathrm{Al}$ liquid. We find that $\mathrm{Cr}$ additions

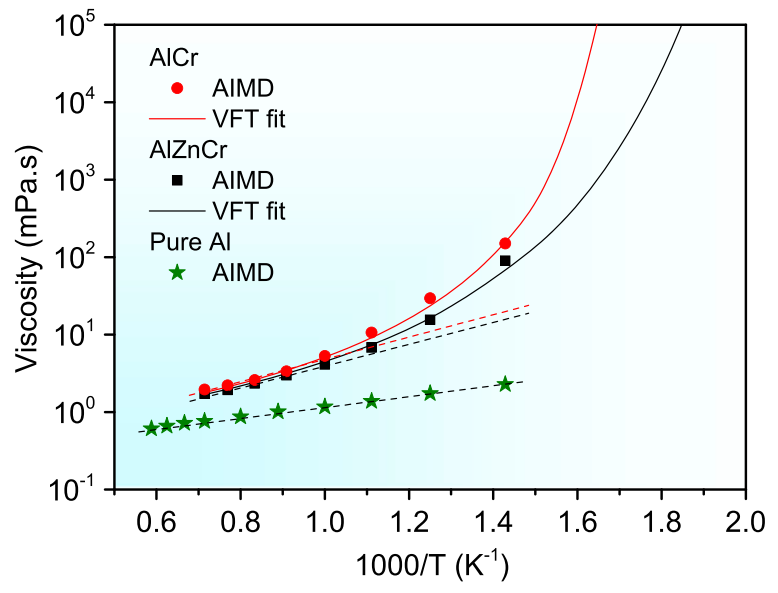

Fig. 3 Arrhenius plot of the viscosity for Al-Cr binary alloy as well as the $\mathrm{Al}-\mathrm{Zn}-\mathrm{Cr}$ ternary alloy. The simulation data for pure liquid $\mathrm{Al}$ are also included for comparison. The dashed lines correspond to the Arrhenius fit in the temperature range $1400-1000 \mathrm{~K}$ for Al-Cr and Al $-\mathrm{Zn}-\mathrm{Cr}$, and a range from 1700 to $700 \mathrm{~K}$ for pure $\mathrm{Al}$

give rise to a significant increase of viscosity in alloys in the undercooling regime. In addition, we show that this effect is slightly more pronounced in $\mathrm{Al}_{93} \mathrm{Cr}_{7}$ in the deep undercooling region. Moreover, the inverse temperature dependence displays a deviation from the Arrhenius fit below $T_{x}=1000$ and $900 \mathrm{~K}$ for $\mathrm{Al}_{93} \mathrm{Cr}_{7}$ and $\mathrm{Al}_{83} \mathrm{Zn}_{10} \mathrm{Cr}_{7}$, respectively, as obtained for self-diffusion coefficients and structural relaxation times.

As for the structural relaxation time, we used the VFT equation to fit the temperature dependence of viscosity, $\eta=\eta_{0} \exp \left(B^{\prime} T_{0}^{\prime} /\left(T-T_{0}^{\prime}\right)\right)$, where $\eta_{0}, B^{\prime}$, and $T_{0}^{\prime}$ are materialdependent parameters and including an additional fitting point, namely $1 \times 10^{12} \mathrm{~Pa} s$ as the standard definition of the viscosity at $T_{\mathrm{G}}$. The VFT fit yields $B^{\prime}=3.51$ and 3.46 and $T_{0}^{\prime}=456 \mathrm{~K}$ and $410 \mathrm{~K}$ in $\mathrm{Al}_{93} \mathrm{Cr}_{7}$ and $\mathrm{Al}_{83} \mathrm{Zn}_{10} \mathrm{Cr}_{7}$, respectively. We can also determine the fragility parameter from $m=B^{\prime} T_{0}^{\prime} T_{\mathrm{G}} /\left[\left(2.3\left(T_{\mathrm{G}}-T_{0}^{\prime}\right)\right)^{2}\right.$. We obtain $m=179$ and 173 in $\mathrm{Al}_{93} \mathrm{Cr}_{7}$ and $\mathrm{Al}_{83} \mathrm{Zn}_{10} \mathrm{Cr}_{7}$, respectively, values which are close to those inferred from the structural relation time. Note that these values are indicative of a high fragility as compared to metallic liquids with high glass-forming ability (GFA). ${ }^{4}$

\section{The Stokes-Einstein relation}

Having computed both self-diffusion coefficients and viscosities, we tested the validity of the SE relation in $\mathrm{Al}_{93} \mathrm{Cr}_{7}$ and $\mathrm{Al}_{83} \mathrm{Zn}_{10} \mathrm{Cr}_{7}$. The evolution of the $D_{i} \eta / T$ ratio as a function of temperature for both liquids is shown in Fig. 4a. At high temperatures, we observe that this ratio is nearly constant for all components in both liquids but for the fastest components, i.e., $\mathrm{Al}$ in $\mathrm{Al}_{93} \mathrm{Cr}_{7}$, and $\mathrm{Al}$ and $\mathrm{Zn}$ in $\mathrm{Al}_{83} \mathrm{Zn}_{10} \mathrm{Cr}_{7}$, the $D_{i} \eta / T$ ratio increases sharply upon cooling. More specifically, the temperature derivative of the ratio for all components in both liquids is drawn in Fig. $4 \mathrm{~b}$ and reveals that the SE relation fails for the fastest components for temperatures below $T_{x}=1000$ and $900 \mathrm{~K}$ for $\mathrm{Al}_{93} \mathrm{Cr}_{7}$ and $\mathrm{Al}_{83} \mathrm{Zn}_{10} \mathrm{Cr}_{7}$, respectively, corresponding to the Arrhenius-to-non-Arrhenius crossover of transport properties investigated above.

Moreover, the $D_{i} \eta / T$ ratio is commonly related to the inverse of an effective $S E$ radius of $i$ component, $R_{i}^{S E} \cdot R_{i}^{S E}$ is often taken from the location of the first maximum in the partial pair-distribution function of $i$ component, $g_{i i}(r)$, shown in Figs. 5 and 6. From Fig. 4a, we can see that the $\mathrm{SE}$ relation gives $R_{\mathrm{Cr}}^{\mathrm{SE}}$ always greater than $R_{\mathrm{AI}}^{\mathrm{SE}}$ and $R_{\mathrm{Zn}}^{\mathrm{SE}}$, which is anti-correlated with the position of the first peak in $g_{i i}(r)$ found in AIMD simulations and shown in the inset of Fig. 4a. Such a behavior has been already observed in other 
4
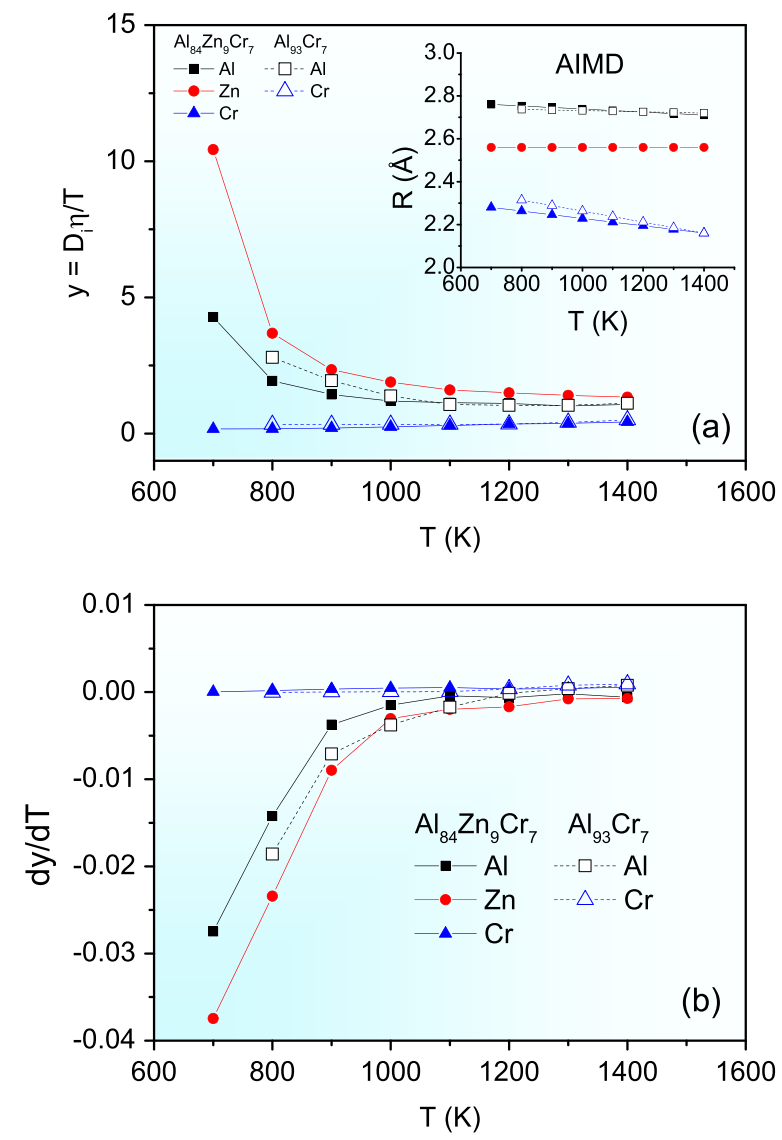

Fig. 4 a Temperature evolution of the Stokes-Einstein ratio $y=D_{i} \eta / T$ for $\mathrm{Al}$ and $\mathrm{Cr}$ atoms in $\mathrm{Al}-\mathrm{Cr}$ binary alloy and $\mathrm{Al}, \mathrm{Zn}$, and $\mathrm{Cr}$ atoms in $\mathrm{Al}-\mathrm{Zn}-\mathrm{Cr}$ ternary alloy. Inset: corresponding radius $\mathrm{R}$ obtained from AIMD partial pair-distribution functions. $\mathbf{b}$ Temperature derivative $\mathrm{dy} / \mathrm{d} T$ for $\mathrm{Al}$ and $\mathrm{Cr}$ atoms in $\mathrm{Al}-\mathrm{Zn}$ binary alloy and $\mathrm{Al}, \mathrm{Zn}$, and $\mathrm{Cr}$ atoms in $\mathrm{Al}-\mathrm{Zn}-\mathrm{Cr}$ ternary alloy

Al-based liquid alloys and indicates that a more refined description of the local structure is mandatory. ${ }^{30,} 31$

Very recently, we have shown that partial excess entropies described in the two-body approximation, i.e., $S_{2}^{i}=$ $-2 \pi \rho \sum_{j=1}^{N} x_{j} \int_{0}^{\infty}\left\{g_{i j}(r) \ln \left[g_{i j}(r)\right]-\left[g_{i j}(r)-1\right]\right\} r^{2} d r$ where $g_{i j}(r)$ is the partial pair-distribution function between component $i$ and $j$, and $x_{j}$ is the composition of component $j$, are valuable structural indicators, able to make a clear correlation between local structural ordering and self-diffusion coefficients in liquid alloys. ${ }^{31}$ For $\mathrm{Al}_{93} \mathrm{Cr}_{7}$ and $\mathrm{Al}_{83} \mathrm{Zn}_{10} \mathrm{Cr}_{7}$, we obtained that $S_{2}^{\mathrm{Cr}}$ is strongly decoupled from $S_{2}^{A l}$ or $S_{2}^{Z n}$ as seen in Supplementary Fig. 5. Moreover, we observe that below $T_{x}, S_{2}^{\mathrm{Cr}}$ in each alloy clearly differs from the linear fit obtained in the high-temperature regime. All these results evidence a direct link between local structural ordering and component decoupling. In addition, we derived a simple relation between the ratio of self-diffusion coefficients of the components and the corresponding partial pair-excess entropies, e.g., $D_{i} / D_{j} \approx S_{2}^{j} / S_{2}^{i}$. ${ }^{31}$ In Fig. 7 , we show that both quantities correlate very well in the two alloys, including the acceleration of the component decoupling upon undercooling. Note also that the rapid evolution of $S_{2}^{\mathrm{Cr}}$ upon cooling can be related to the fragile character of both alloys. Therefore, to get deeper insight into this correlation, we analyzed in more details the structural process underlying the evolution of transport properties as a function of temperature.

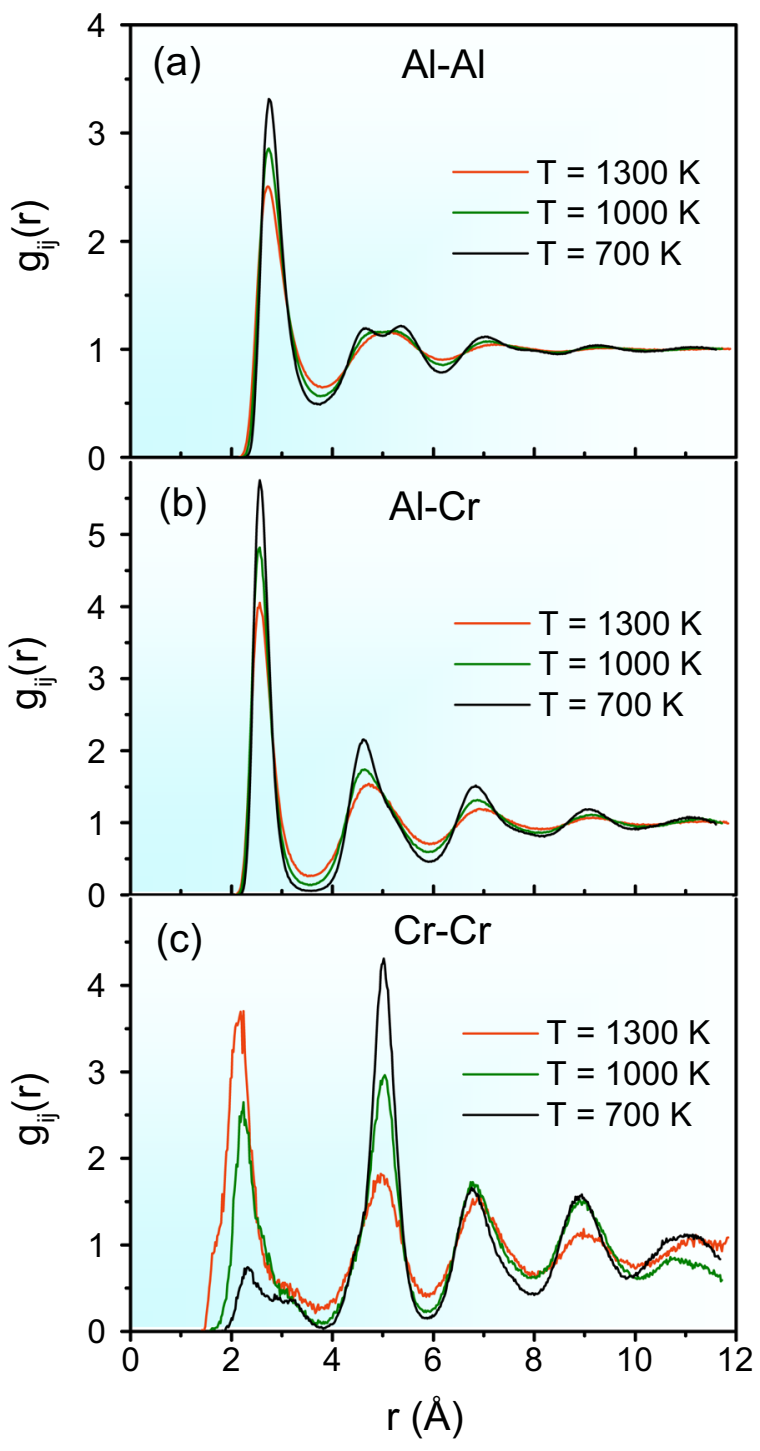

Fig. 5 Calculated partial pair-distribution functions of $\mathrm{Al}-\mathrm{Cr}$ binary alloy from ab initio molecular dynamics simulations for various temperatures: a $\mathrm{Al}-\mathrm{Al}, \mathbf{b} \mathrm{Al}-\mathrm{Cr}$, and $\mathbf{c} \mathrm{Cr}-\mathrm{Cr}$. The data for 700 and $1000 \mathrm{~K}$ are taken from ref. 24

Degree of fivefold local symmetry

Several structural indicators have been invoked to detect a structural signature in transport properties. ${ }^{32}$ Among them, we have previously evidenced that the degree of fivefold symmetry (FFS) in local ordering plays a key role in seeking a structural basis for Al-based liquid dynamics. ${ }^{30-32}$ Here, we monitored this degree of FFS using the common-neighbor analysis. ${ }^{33}$ It is given by the sum of 1551, 1541, and 1431 bonded pairs averaged over the alloying components and which include both perfect and distorted fivefold topology. Twenty inherent configurations are used to determine FFS at each temperature. Note that for each alloy, we also report FFS for two temperatures below their glass transition, namely $T=500$ and $400 \mathrm{~K}$ for $\mathrm{Al}_{93} \mathrm{Cr}_{7}$ and $T=400$ and $300 \mathrm{~K}$ for $\mathrm{Al}_{83} \mathrm{Zn}_{10} \mathrm{Cr}_{7}$.

Figure 8a shows the temperature dependence of FFS in both liquids, as well as the temperature dependence of their viscosity for comparison. It is obvious that $\eta$ and FFS follow a similar temperature dependence in the investigated range of temperature, indicating that the evolution of FFS may play a key role in the 

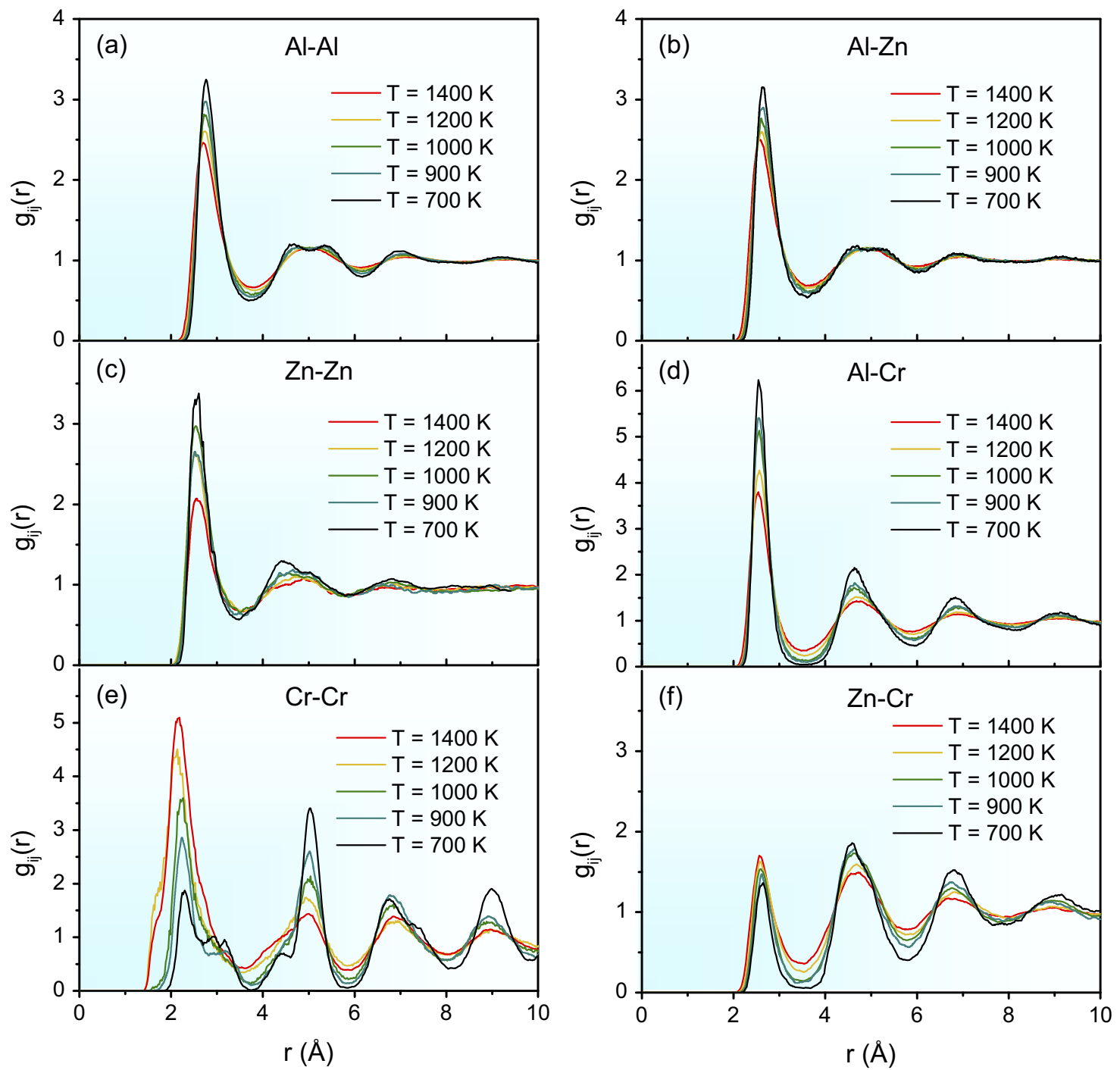

Fig. 6 Calculated partial pair-distribution functions of $\mathrm{Al}-\mathrm{Zn}-\mathrm{Cr}$ ternary alloy from ab initio molecular dynamics simulations for various temperatures: a Al-Al, b Al- $\mathrm{Zn}, \mathbf{c} \mathrm{Zn}-\mathrm{Zn}$, d Al-Cr, e $\mathrm{Cr}-\mathrm{Cr}$, and f $\mathrm{Zn}-\mathrm{Cr}$

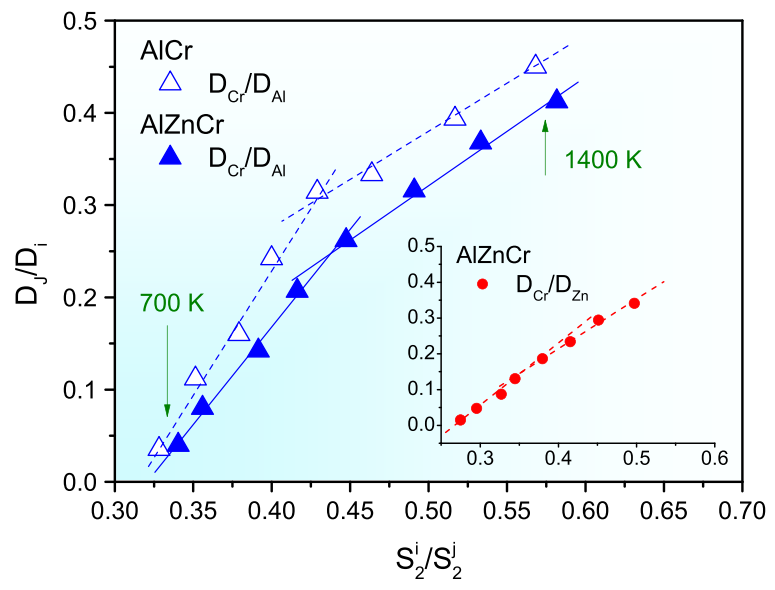

Fig. 7 Ratio of the self-diffusion coefficients $D_{i} / D_{j}$ as function of $S_{2}^{j} / S_{2}^{i}$ for $\mathrm{Al}-\mathrm{Cr}$ binary alloy, as well as the $\mathrm{Al}-\mathrm{Zn}-\mathrm{Cr}$ ternary alloy, as well as for the inset change in viscosity. Note that our results are in close agreement with those obtained by $\mathrm{Hu}$ et al. $^{34}$ using another approach to determine FFS, based on the Voronoi analysis. However, a more detailed analysis in the deep undercooling regime evidences that the increase of viscosity is more rapid in $\mathrm{Al}_{93} \mathrm{Cr}_{7}$ than in $\mathrm{Al}_{83} \mathrm{Zn}_{10} \mathrm{Cr}_{7}$ while the evolution of FFS is similar in both alloys. Moreover, it is clear that this averaged FFS is not enough to explain the decoupling of self-diffusion coefficients in $\mathrm{Al}_{93} \mathrm{Cr}_{7}$ and $\mathrm{Al}_{83} \mathrm{Zn}_{10} \mathrm{Cr}_{7}$.

In Fig. $8 \mathrm{~b}$ we display the correlation between FFS values of each component and the corresponding self-diffusion coefficient of both alloys in the investigated temperature range. The striking observation is the strong difference in partial FFS around $\mathrm{Al}$ (Al and $\mathrm{Zn}$ ) and $\mathrm{Cr}$ in $\mathrm{Al}_{93} \mathrm{Cr}_{7}\left(\mathrm{Al}_{83} \mathrm{Zn}_{10} \mathrm{Cr}_{7}\right)$ reaching a factor as large as 1.5 even in the high-temperature regime. It is also obvious that the decrease of mobility of each component is in phase with the increase of partial FFS. As a matter of fact, FFS is known to give rise to very compact local structures and then to favor the backscattering regime that is predominant in liquid Al-based alloys. Indeed, a high local symmetry causes a backflow of the atoms induced by the caging effect and then increases the ability of an atom to jump back toward its initial position. ${ }^{35}$ As a consequence, 

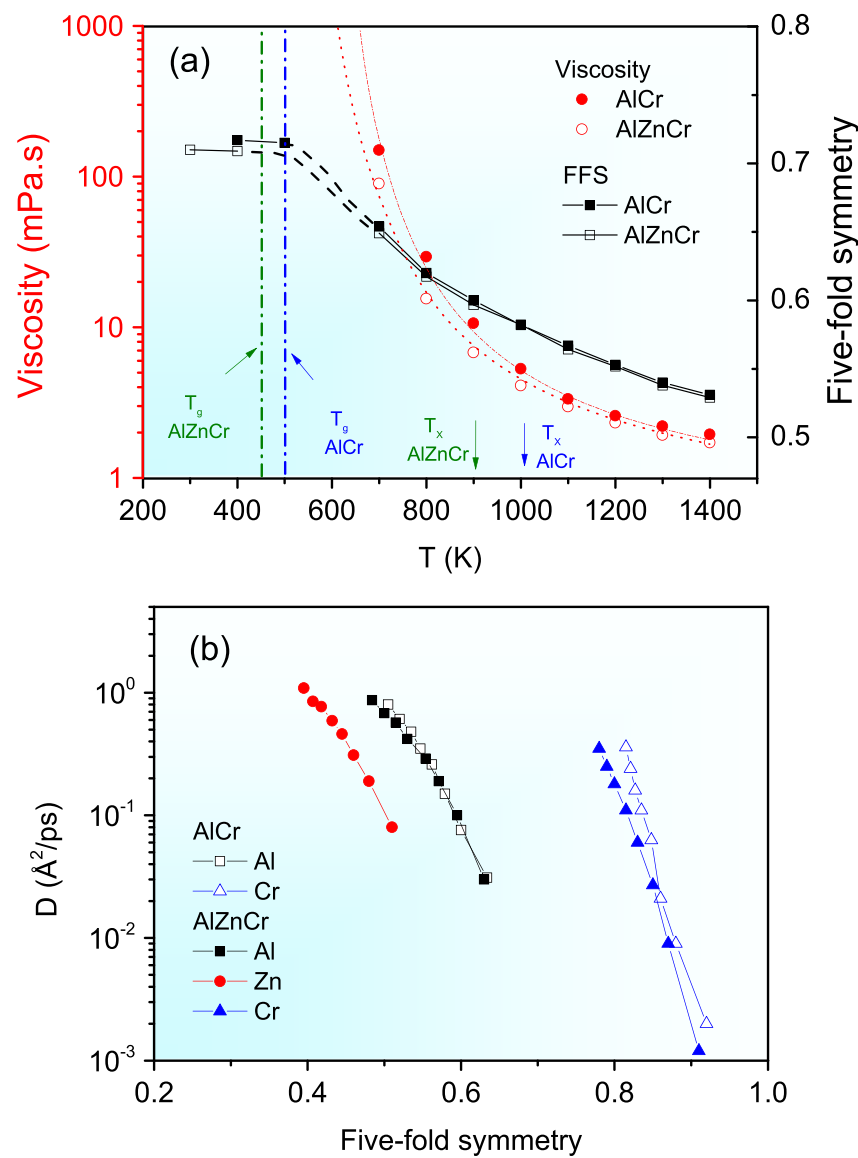

Fig. 8 a Fivefold symmetry (FFS) and viscosity for $\mathrm{Al}-\mathrm{Cr}$ binary alloy and the $\mathrm{Al}-\mathrm{Zn}-\mathrm{Cr}$ ternary alloy. The dashed-dotted and dashed lines are the respective VFT fits. b Self-diffusion coefficients as a function of the FFS values for $\mathrm{Al}$ and $\mathrm{Cr}$ atoms in $\mathrm{Al}-\mathrm{Cr}$ binary alloy and $\mathrm{Al}$, $\mathrm{Zn}$, and $\mathrm{Cr}$ atoms in $\mathrm{Al}-\mathrm{Zn}-\mathrm{Cr}$ ternary alloy

the higher is FFS the lower the diffusivity. Our results clearly demonstrate that atomic mobility in these liquids directly correlates to FFS of each component but an additional structural analysis is necessary to understand the origin of this strong difference in partial FFS.

\section{Partial pair-distribution functions}

To go further, we analyzed the local ordering of each component in both alloys via the partial pair-distribution functions. Figures $5 a-c$ and $6 a-f$ show the temperature dependence of partial pair-distribution functions of liquid $\mathrm{Al}_{93} \mathrm{Cr}_{7}$ and $\mathrm{Al}_{83} \mathrm{Zn}_{10} \mathrm{Cr}_{7}$ alloys, respectively. They are obtained from 1000 independent equilibrated configurations at each temperature and we refer the reader to ref. 36 for a detailed description of standard techniques to extract them. For the sake of clarity, we display only five temperatures over the investigated range, as each $g_{i j}(r)$ displays a linear temperature dependence.

From Figs. 5a and $6 a-c$, we can see that the height of the first peak of $g_{\text {AlAl }}(r), g_{\text {AIZn }}(r)$, and $g_{\mathrm{ZnZn}}(r)$ increases upon cooling as usually observed in many metallic liquids. But more information can be obtained in the temperature dependence of $g_{\mathrm{AlCr}}(r), g_{\mathrm{CrCr}}(r)$, and $g_{\mathrm{ZnCr}}(r)$ as seen in Figs. $5 \mathrm{~b}, \mathrm{c}$ and $6 \mathrm{~d}-\mathrm{f}$. First, it should be noticed that these partials involving $\mathrm{Cr}$ atoms are more structured, characterized by a first minimum which becomes significantly low in the undercooling regime, leading to a well-defined first-nearestneighbor shell around each $\mathrm{Cr}$ atom upon cooling. Then, we note that the first peak in $g_{\mathrm{AlCr}}(r)$ increases strongly with decreasing (a)

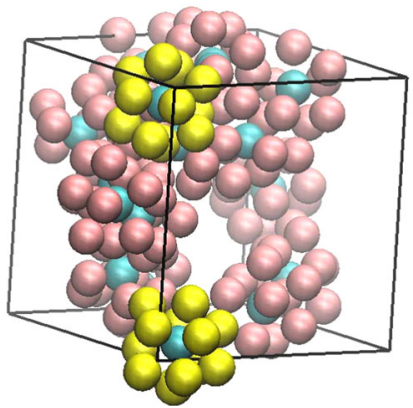

(b)

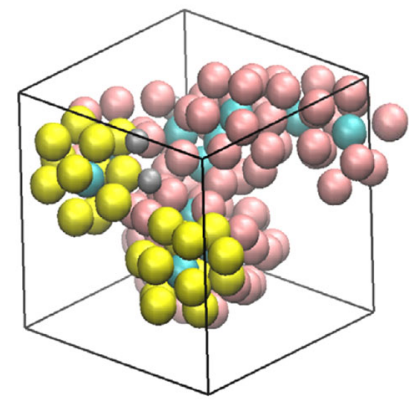

Fig. 9 Snapshots of the simulation for: a Al-Cr binary alloy where nearest-neighbor environment of $\mathrm{Cr}$ atoms, extracted from an equilibrium configuration obtained in the AIMD simulation at $T=$ $800 \mathrm{~K}$, are shown. They consist in 160 atoms out of the 256 atoms simulation box, namely $142 \mathrm{Al}$ atoms in dark pink and $18 \mathrm{Cr}$ atoms in blue. b $\mathrm{Al}-\mathrm{Zn}-\mathrm{Cr}$ ternary alloy where also nearest-neighbor environment of $\mathrm{Cr}$ atoms, extracted from an equilibrium configuration obtained in the AIMD simulation at $T=800 \mathrm{~K}$, are shown. They consist in 146 atoms out of the 256 atoms with $124 \mathrm{Al}, 4 \mathrm{Zn}$, and 18 $\mathrm{Cr}$ atoms, resulting in a local composition $\mathrm{Al}_{85} \mathrm{Zn}_{3} \mathrm{Cr}_{12}$. For both panels, $\mathrm{Al}, \mathrm{Zn}$, and $\mathrm{Cr}$ atoms are drawn, respectively, in dark pink, gray, and blue color. Moreover, Al atoms in two typical Cr-centered icosahedra are highlighted in yellow for visual purpose. Some of the atoms in the configuration are shown outside the simulation cell by application of the periodic boundary conditions

temperature and displays the highest amplitude, which is an indication of the formation of preferred $\mathrm{Al}-\mathrm{Cr}$ bonds in both alloys. Such a result is corroborated by the weak amplitude of the first peak of the $\mathrm{Zn}-\mathrm{Cr}$ partial in the ternary alloy which becomes even smaller than the second peak in the undercooling regime. Then we can conclude that $\mathrm{Cr}$ atoms are mainly surrounded by $\mathrm{Al}$ atoms in both alloys. In addition, the well-defined first-nearestneighbor shell can be related to the important caging effect observed in the diffusivity of $\mathrm{Cr}$ atoms.

Yet the most striking feature is clearly seen in Figs. $5 \mathrm{c}$ and $6 \mathrm{e}$ where we observe a strong decrease of the first peak of $g_{\mathrm{CrCr}}(r)$ while the second peak increases in both alloys. Below $T_{x}$, the crossover temperature in transport properties, the height of the second peak becomes higher than that of the first peak and the subsequent oscillations become more significant. Such an evolution is in favor of an extension of local ordering to larger distances upon cooling ${ }^{37}$ and leads us to the conclusion that the undercooled state is characterized by the development of a medium-range order (MRO) referring to $\mathrm{Cr}$ atoms.

We plot in Fig. 9a, b the real three-dimensional snapshot of the MRO for each alloy in the undercooling regime, at $T=800 \mathrm{~K}$. A rapid inspection indicates that MRO consists of a chain-like arrangement of $\mathrm{Cr}$-centered icosahedra connected via $\mathrm{Al}$ atoms present in their first-nearest-neighbor shells. Only two typical $\mathrm{Cr}$ centered icosahedra formed by Al atoms are highlighted in yellow for visual purpose. As described in our preceding work ${ }^{38}$ icosahedra can be linked to each other by sharing atoms through vertex, edge, face, and pentagonal cap (intercross), called modes of interconnection. Here, we can observe from Fig. 9a, b modes of interconnection between these icosahedra like edge-shared and intercross-shared ones, indicating an increase of the dense random packing in this region. ${ }^{39}$

In addition, the development of this IMRO with the strong intermixing between $\mathrm{Cr}$ and $\mathrm{Al}$ atoms yields an atomic-scale heterogeneity because those $\mathrm{Al}$ atoms being the first-nearest neighbors of $\mathrm{Cr}$ atoms are less numerous than expected from the alloy composition. More specifically, the chemical composition of IMRO is $\mathrm{Al}_{88} \mathrm{Cr}_{12}$ in $\mathrm{Al}_{93} \mathrm{Cr}_{7}$ while it is $\mathrm{Al}_{85} \mathrm{Zn}_{3} \mathrm{Cr}_{12}$ in $\mathrm{Al}_{83} \mathrm{Zn}_{10} \mathrm{Cr}_{7}$. We also report that at $T=800 \mathrm{~K}$, the percentage of atoms present in 

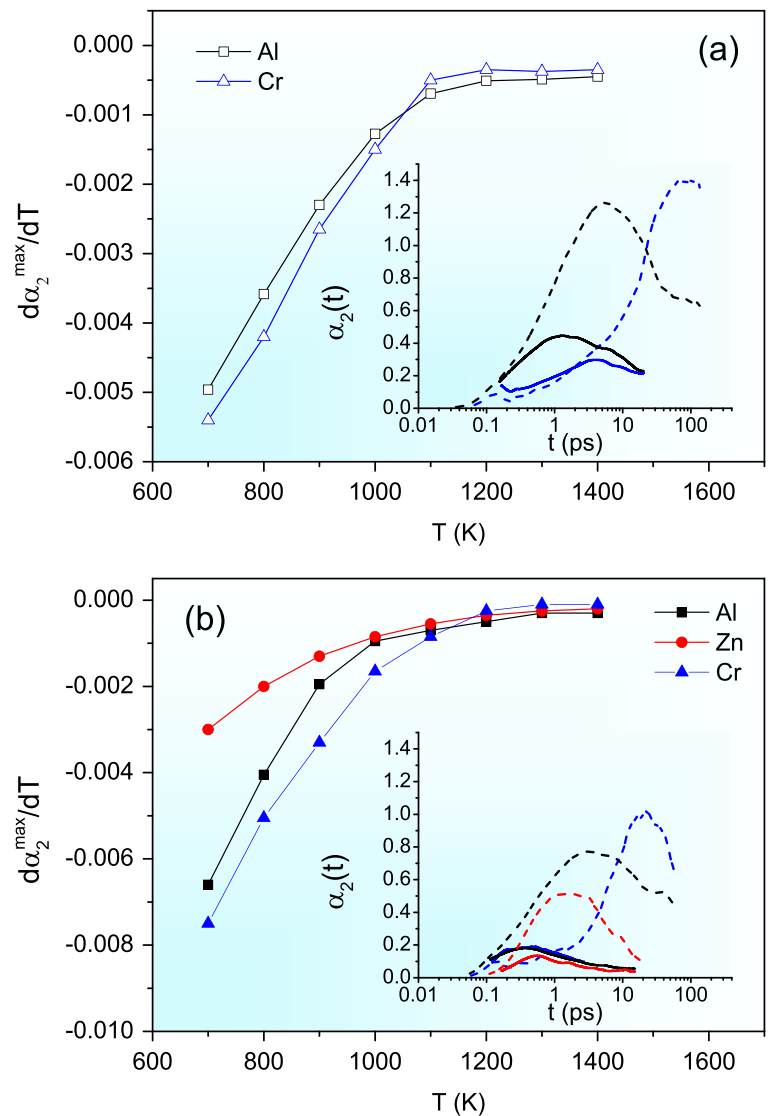

Fig. 10 a Temperature derivative $\mathrm{d} a_{2}^{\max } / \mathrm{d} T$ for $\mathrm{Al}$ and $\mathrm{Cr}$ as a function of temperature for $\mathrm{Al}$ and $\mathrm{Cr}$. Inset: Non-Gaussian parameter of $\mathrm{Al}$ and $\mathrm{Cr}$ for temperatures $T=1100$ and $700 \mathrm{~K}$. b Temperature derivative $\mathrm{d} a_{2}^{\max } / \mathrm{d} T$ as a function of temperature for $\mathrm{Al}, \mathrm{Zn}$, and $\mathrm{Cr}$ atoms in $\mathrm{Al}-\mathrm{Zn}-\mathrm{Cr}$ ternary alloy. Inset: Non-Gaussian parameter of $\mathrm{Al}, \mathrm{Zn}$, and $\mathrm{Cr}$ atoms for temperatures $T=1400$ and $800 \mathrm{~K}$

IMRO is less important in $\mathrm{Al}_{83} \mathrm{Zn}_{10} \mathrm{Cr}_{7}$ than in $\mathrm{Al}_{93} \mathrm{Cr}_{7}$, e.g., 50 and $56 \%$, respectively. In other words, IMRO is slightly less developed in $\mathrm{Al}_{83} \mathrm{Zn}_{10} \mathrm{Cr}_{7}$ than in $\mathrm{Al}_{93} \mathrm{Cr}_{7}$.

\section{DISCUSSION}

We have firmly established a correlation between transport properties and the FFS. Yet, as already discussed above, it is clear that FFS observed in local ordering is not sufficient to reveal a structural mechanism for the dynamic slowdown in the deep undercooling regime. However, as we observe the development of IMRO in this regime, one can question whether this IMRO can constitute a structural signature of the emergence of DHs.

\section{Non-Gaussian parameter}

We first quantified the emergence of DHs. The latter can be revealed from the non-Gaussian parameter (NPG), by following the evolution of its maximum value $a_{2}^{\max }$. Namely, dramatic increase of $a_{2}^{\max }$ above a value of 0.2 corresponds to an increasing degree of $\mathrm{DH}$. Then, the change of $a_{2}^{\max }$ with temperature can be illustrated more clearly by the first derivative of $a_{2}^{\max }$ against temperature, $\mathrm{d} a_{2}^{\max } / \mathrm{d} T$. In Fig. 10a, b, we display $\mathrm{d} a_{2}^{\max } / \mathrm{d} T$ for each component of both alloys. The temperature dependence of $\mathrm{d} a_{2}^{\max } / \mathrm{d} T$ reveal that $\mathrm{DHs}$ become gradually more and more important in the undercooled regime. However, we find that this evolution is more significant for $\mathrm{Al}$ and $\mathrm{Cr}$ components than for $\mathrm{Zn}$ component in the ternary alloy. Such a strong increase of the DHs can also be seen on the curves of $a_{2}(t)$ themselves, as shown in the inset of Fig. 10a, b. We note also that DHs emerge almost at the same time when the breakdown of the SE relation occurs. However, at $T_{x}$, the emergence of DHs is found for each component of the two alloys while the breakdown of the SE relation occurs for fast components only, $\mathrm{Al}$ in $\mathrm{Al}_{93} \mathrm{Cr}_{7}$ and $\mathrm{Al}$ and $\mathrm{Zn}$ in $\mathrm{Al}_{83} \mathrm{Zn}_{10} \mathrm{Cr}_{7}$.

\section{Spatial distribution}

We now determine the spatial distribution of $\mathrm{DHs}$ for both alloys by means of isoconfigurational ensemble simulations using the same procedure as in our preceding work. ${ }^{24}$ The propensity maps for $\mathrm{Al}_{93} \mathrm{Cr}_{7}$ and $\mathrm{Al}_{83} \mathrm{Zn}_{10} \mathrm{Cr}_{7}$ are plotted in Fig. $11 \mathrm{a}$, b. They reveal a well pronounced heterogeneous structure in both alloys displaying alternation of sites with high propensity and large domains of low propensity. Interesting enough is the spatial distribution of $\mathrm{Cr}$ atoms that we show for both alloys in Fig. 11c, d. Comparing the latter with Fig. 11a, b, allows us to make a correlation between $\mathrm{Cr}$ atoms positions and the domains of low propensity. Nevertheless, a better long-range connection between $\mathrm{Cr}$ atoms in $\mathrm{Al}_{93} \mathrm{Cr}_{7}$ than in $\mathrm{Al}_{83} \mathrm{Zn}_{10} \mathrm{Cr}_{7}$ can be seen, which is in phase with the greater development of IMRO in $\mathrm{Al}_{93} \mathrm{Cr}_{7}$. Then we can conclude, as was already pointed out in our preceding work ${ }^{24}$ that IMRO is responsible for slow dynamics. Furthermore, localized fastdynamic regions are formed by $\mathrm{Al}$ atoms only in $\mathrm{Al}_{93} \mathrm{Cr}_{7}$, and solely $\mathrm{Al}$ and $\mathrm{Zn}$ atoms in $\mathrm{Al}_{83} \mathrm{Zn}_{10} \mathrm{Cr}_{7}$. We also established a clear correlation between the component decoupling and the chemical composition of fast-dynamic and low-dynamic regions.

In summary, we evidenced a relationship between the decoupling of diffusivity in the liquid phase and the emergence of $\mathrm{DH}$ s in the undercooled regime for some Al-based liquids. Both phenomena are related to the same structural mechanism, characterized by a strong interplay between chemical shortrange order (Al-Cr affinity) and a high degree of FFS around $\mathrm{Cr}$ component. This structural mechanism gives rise to different local ordering in the liquid phase and the rapid development of IMRO in the undercooled regime by interconnecting $\mathrm{Cr}$ atoms by their first-nearest Al neighbors. It also explains the high fragility obtained in these liquids. Our results demonstrate that a structural signature which incorporates medium-range order is necessary to constitute a robust relationship with liquid dynamics. Interestingly, this structural signature is contained in the temperature dependence of partial pair-distribution functions which are still in the scope of experimental studies. Therefore, our theoretical study opens up the route to more refined structural analysis capable of quantifying the temperature dependence of partial pairdistribution functions upon undercooling.

\section{METHODS}

The methods used in this paper follow those in our previous work, ${ }^{24}$ and are recalled below.

Ab initio molecular dynamics

For both alloys, the AIMD simulations are performed in the NVT ensemble using dynamics based on forces from the projector augmented wave (PAW) method as implemented in the Vienna ab initio simulation package $\left(\right.$ VASP) ${ }^{40}$ within the local density approximation (LDA). ${ }^{41,42} \mathrm{~A}$ number of 256 atoms with the given composition is arranged in a cubic simulation box with standard periodic boundary conditions. Only the $\Gamma$ point is used to sample the Brillouin zone. We have shown that such approximations reproduce the transport properties of liquid aluminum correctly. ${ }^{43}$ The sample is equilibrated using a Nosé thermostat at $T=1400 \mathrm{~K}$ and the temperature evolution is obtained by quenching the system by temperature step of $100 \mathrm{~K}$ up to $700 \mathrm{~K}$ with an average cooling rate of $3 \times 10^{12} \mathrm{~K} / \mathrm{s}$. At each temperature, the volume $V$ of the simulation cell was chosen to reproduce the experimental densities. ${ }^{27}$ The pressures 
(a)

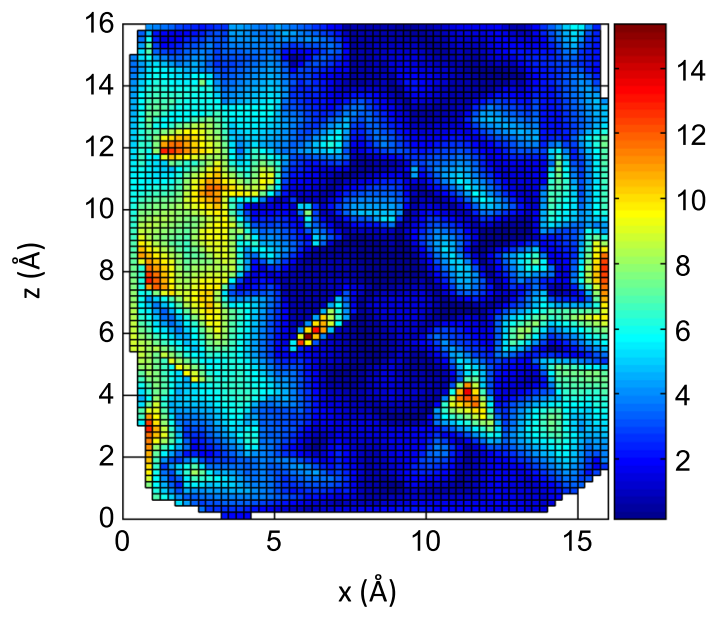

(c)

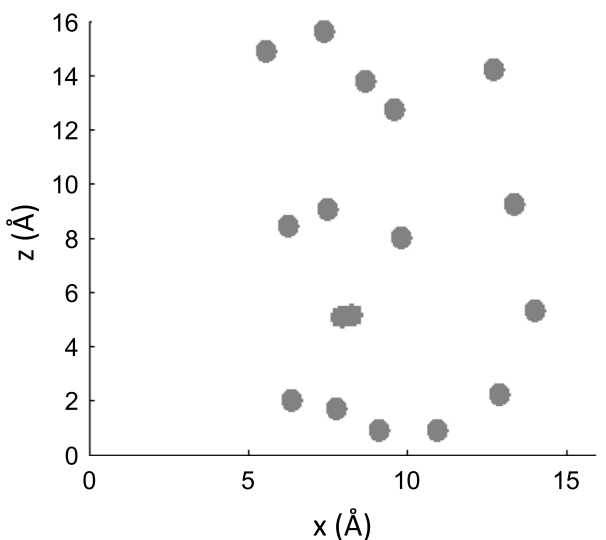

(b)

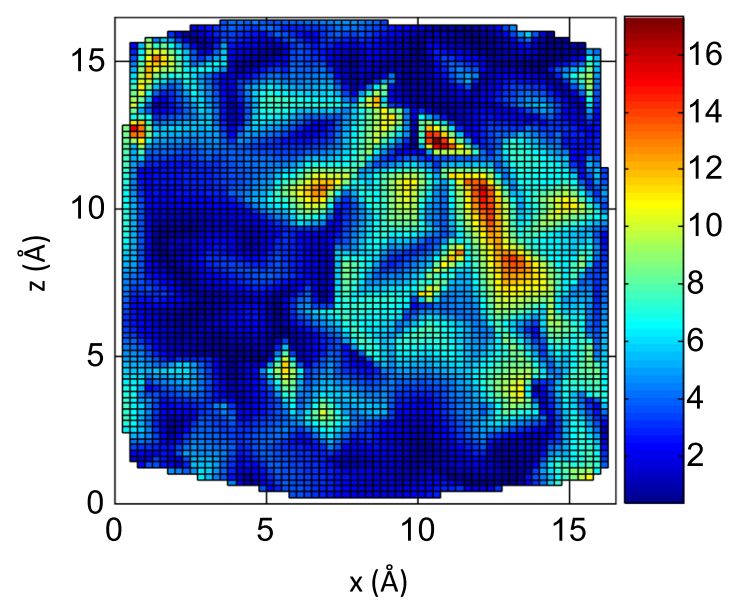

(d)

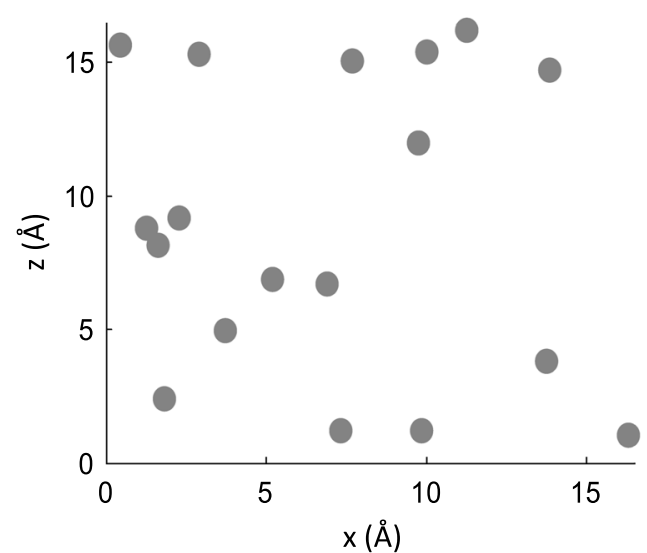

Fig. 11 Propensity map of all atoms in the simulation box for a Al- $\mathrm{Cr}$ binary alloy at $T=800 \mathrm{~K}, \mathbf{b} \mathrm{Al}-\mathrm{Zn}-\mathrm{Cr}$ ternary alloy $T=800 \mathrm{~K}$. The color scale corresponds to the propensity in Angstrom squared. Positions of the $\mathrm{Cr}$ atoms in the initial configuration of the isoconfigurational simulations c Al- $\mathrm{Cr}$ binary alloy at $T=800 \mathrm{~K}$. d Al- $\mathrm{Zn}-\mathrm{Cr}$ ternary alloy $T=800 \mathrm{~K}$. Panels a and $\mathrm{c}$ are drawn from ref. 24 by permission of the American Physical Society

calculated in the simulation cell do not exceed $0.9 \mathrm{GPa}$ with a typical fluctuation of $1.2 \mathrm{GPa}$. Above the liquidus temperature, the run is continued for equilibration during a time up $120 \mathrm{ps}$ while $400 \mathrm{ps}$ are used in the undercooled region. For $T=700 \mathrm{~K}$, the equilibration is continued up to $700 \mathrm{ps}$. For each temperature, the equilibration time represents at least twice the relaxation time of the liquid alloy, which ensures the determination of structural and dynamic properties under equilibrium condition with a good statistical accuracy.

\section{Transport properties}

For the dynamics, we focus on the self-diffusion coefficients, the relaxation phenomena and viscosities.

Self-diffusion coefficients are characterized by the individual atom displacement through the mean-square displacement for each component $i(i=\mathrm{Al}, \mathrm{Zn}$ or $\mathrm{Cr})$

$R_{i}^{2}(t)=\frac{1}{N_{i}} \sum_{k=1}^{N_{i}}\left\langle\left[\mathbf{r}_{k}\left(t+t_{0}\right)-\mathbf{r}_{k}\left(t_{0}\right)\right]^{2}\right\rangle_{t_{0}}$,

where $\mathbf{r}_{k}(t)$ represents the position of atom $k$ of specie $i$ at time $t$. The angular brackets represent the average over time origins $t_{0}$. The selfdiffusion coefficient $D_{i}$ can be determined from the long time slope of $R_{i}^{2}(t)$, namely:

$D_{i}=\lim _{t \rightarrow \infty} \frac{R_{i}^{2}(t)}{6 t}$.
Relaxation phenomena can be studied through the structural relaxation time. To obtain this quantity, we start from the self-part of the van Hove $(\mathrm{vH})$ function that is defined for each component $i$ by:

$G_{s, i}(r, t)=\frac{1}{N_{i}}\left\langle\sum_{k=1}^{N_{i}} \delta\left(r-\left|\mathbf{r}_{k}\left(t+t_{0}\right)-\mathbf{r}_{k}\left(t_{0}\right)\right|\right)\right\rangle_{t_{0}}$.

The function $G_{S}(r, t)$ gives a measure of the probability that a given particle has undergone a displacement $r$ in after a time $t$ from the time origin $t_{0}$. Spatial Fourier Transform of $G_{S}(r, t)$ yields the self-intermediate scattering function

$F_{s, i}(q, t)=\frac{1}{N_{i}}\left\langle\sum_{k=1}^{N_{i}} \exp \left[i \mathbf{q}\left(\mathbf{r}_{k}\left(t+t_{0}\right)-\mathbf{r}_{k}\left(t_{0}\right)\right)\right]\right\rangle_{t_{0}}$,

where $q=(2 \pi / L)\left(n_{x}, n_{y}, n_{z}\right)$ are wave vectors compatible with the length $L=V^{1 / 3}$ of the simulation cell and $n_{x}, n_{y}$, and $n_{z}$ are integers. At long times, $F_{s}(q, t)$ should undergo a final decay, known as the a-relaxation process characteristic of the diffusive regime, from which the structural relaxation time $\tau_{a}$ can be determined. More in details, the a-relaxation time, $\tau_{a}$, is obtained at the time needed for the corresponding self-intermediate scattering function $F_{s}(q, t)$ at the first peak of $S(q)$ to be equal to $1 / e^{44}$ The wave vector $\mathrm{q}$ is fixed at $|\mathrm{q}|=q_{\text {max }}$, the first peak position in structure factor, e.g., $q_{\max }=2.75 \AA^{-1}$ and $2.90 \AA^{-1}$ in $\mathrm{Al}_{93} \mathrm{Cr}_{7}$ and $\mathrm{Al}_{83} \mathrm{Zn}_{10} \mathrm{Cr}_{7}$, respectively.

The shear viscosity is another key transport property describing the macroscopic liquid state dynamics and can be computed from a direct 
method using the transverse current-current correlation function $C_{T}(q, t)$ as in our previous study. ${ }^{29}$ In brief, $C_{T}(q, t)$ is defined as

$C_{T}(q, t)=\frac{1}{N}\left\langle J_{T}^{*}(q, t) J_{T}(q, t)\right\rangle$,

where $J_{T}(q, t)$ is the transverse current expressed along the $x$ direction as

$J_{T}(q, t)=\sum_{p=1}^{N} v_{p, x}(t) \exp \left[j q z_{p}(t)\right]$,

where the quantity $v_{p, x}(t)$ is the $x$-component of the velocity of atom $p$.

The zero limit Laplace transform $\tilde{C}: T(q, z=0)$ gives rise to the $q$ dependent shear viscosity

$\eta(q)=\frac{\rho k_{B} T}{m q^{2} \tilde{C}_{T}(q, z=0)}$,

$k_{B}$ and $m$ correspond respectively to Boltzmann's constant and the weighted average atomic mass, and $\rho$ is the number density. The shear viscosity $\eta$ is thus obtained at the hydrodynamic limit of $\eta(q)$ namely at $q=$ 0 the simulated value of $\eta(q)$ being extrapolated efficiently with the function designed initially to represent the viscosity of a dense hardsphere system ${ }^{45,46}$

$\eta(q)=\frac{\eta}{1+a^{2} q^{2}}$

We have shown in our preceding contributions ${ }^{43}$ that this procedure leads to reliable values of the shear viscosity for metallic liquids with an uncertainty of the order of $0.2 \mathrm{mPa}$.

The non-Gaussian parameter is defined as

$a_{2}(t)=3 R^{4}(t) / 5\left[R^{2}(t)\right]^{2}$,

where $R^{2}(t)$ and $R^{4}(t)$ are respectively the mean-square displacement and mean-quadruple displacement of one component.

\section{Data availability}

The data sets generated during and/or analyzed during the current study are available from the corresponding author on reasonable request.

\section{ACKNOWLEDGEMENTS}

We acknowledge the CINES and IDRIS under Project $N^{\circ}$ INP2227/72914 as well as PHYNUM CIMENT for computational resources. This work was performed within the framework of the Centre of Excellence of Multifunctional Architectured Materials "CEMAM" n'ANR-10-LABX-44-01 funded by the "Investments for the Future" Program.

\section{AUTHOR CONTRIBUTIONS}

N.J. and A.P. conceived the research, performed simulations, discussed and wrote the manuscript. Correspondence and requests for materials should be addressed to N.J.

\section{ADDITIONAL INFORMATION}

Supplementary Information accompanies the paper on the npj Computational Materials website (doi:10.1038/s41524-017-0034-y).

Competing interests: The authors declare that they have no competing financial interests.

Publisher's note: Springer Nature remains neutral with regard to jurisdictional claims in published maps and institutional affiliations.

\section{REFERENCES}

1. Angell, C. A. Formation of glasses from liquids and biopolymers. Science $\mathbf{2 6 7}$ 1924-1935 (1995).

2. Debenedetti, P. G. \& Stillinger, F. H. Supercooled liquids and the glass transition. Nature 410, 259-267 (2011)

3. Tanaka, H., Kawasaki, T., Shintani, H. \& Watanabe, K. Critical-like behaviour of glass-forming liquids. Nat. Mater. 9, 324-331 (2010).

4. Royal, C. P. \& Williams, S. R. The role of local structure in dynamical arrest. Phys. Rep. 560, 1-75 (2015)

5. Mauro, N. A., Blodgett, M., Johnson, M. L., Vogt, A. J. \& Kelton, K. F. A structural signature of liquid fragility. Nat. Commun. 5, 4616 (2014).
6. Ediger, M. D. \& Harrowell, P. Perspective: supercooled liquids and glasses. J. Chem. Phys. 137, 080901 (2012).

7. Kob, W., Donati, C., Plimpton, S. J., Poole, P. H. \& Glotzer, S. C. Dynamical heterogeneities in a supercooled Lennard-Jones liquid. Phys. Rev. Lett. 79, 2827-2830 (1997).

8. Widmer-Cooper, A., Harrowell, P. \& Fynewever, H. How reproducible are dynamic heterogeneities in a supercooled liquid? Phys. Rev. Lett. 93, 135701 (2004).

9. Berthier, L. \& Biroli, G. Theoretical perspective on the glass transition and amorphous materials. Rev. Mod. Phys. 83, 587-645 (2011).

10. Mallamace, F. et al. Transport properties of glass-forming liquids suggest that dynamic crossover temperature is as important as the glass transition temperature. Proc. Natl Acad. Sci. USA 107, 22457-22462 (2010).

11. Tarjus, G. \& Kivelson, D. Breakdown of the Stokes-Einstein relation in supercooled liquids. J. Chem. Phys. 103, 3071-3073 (1995).

12. Bordat, P., Afffouard, F., Descamps, M. \& Müller-Plathe, F. The breakdown of the Stokes-Einstein relation in supercooled binary liquids. J. Phys. Condens. Matter. 15, 5397-5407 (2003).

13. Becker, S. R., Poole, P. H. \& Starr, F. W. Fractional Stokes-Einstein and DebyeStokes-Einstein relations in a network-forming liquid. Phys. Rev. Lett. 97, 055901 (2006).

14. Kumar, S. K., Szamel, G. \& Douglas, J. F. Nature of the breakdown in the StokesEinstein relationship in a hard sphere fluid. J. Chem. Phys. 124, 214501 (2006).

15. $\mathrm{Xu}, \mathrm{L}$. et al. Appearance of a fractional Stokes-Einstein relation in water and a structural interpretation of its onset. Nat. Phys. 5, 565-569 (2009).

16. Ito, K., Moynihan, C. T. \& Angell, C. A. Thermodynamic determination of fragility in liquids and a fragile-to-strong liquid transition in water. Nature 398, 492-495 (1999).

17. Martinez, L. M. \& Angell, C. A. A thermodynamic connection to the fragility of glass-forming liquids. Nature 410, 663-667 (2001).

18. Sastry, S., Debenedetti, P. G. \& Stillinger, F. H. Signatures of distinct dynamical regimes in the energy landscape of a glass-forming liquid. Nature 393, 554-557 (1998).

19. Ngai, K. L. Alternative explanation of the difference between translational diffusion and rotational diffusion in supercooled liquids. J. Phys. Chem. B 103, 10684-10694 (1999).

20. Jakse, N. \& Pasturel, A. Relationship between structural and dynamic properties of Al-rich Al-Cu melts: beyond the Stokes-Einstein relation. Phys. Rev. B 94, 224201 (2016).

21. Mazza, M. G., Giovambattista, N., Starr, F. W. \& Stanley, H. E. Relation between rotational and translational dynamic heterogeneities in water. Phys. Rev. Lett. 96, 057803 (2006).

22. Basuki, S. W. et al. Decoupling of component diffusion in a glass-forming $\mathrm{Zr}_{46.75} \mathrm{Ti}_{8.25} \mathrm{Cu}_{7.5} \mathrm{Ni}_{10} \mathrm{Be}_{27.5}$ melt far above the liquidus temperature. Phys. Rev. Lett. 113, 165901 (2014)

23. Kurtuldu, G., Jarry, P. \& Rappaz, M. Influence of icosahedral short range order on diffusion in liquids: a study on Al-Zn-Cr alloys. Acta Mater. 115, 423-433 (2016).

24. Jakse, N. \& Pasturel, A. Coupling between dynamic slowing down and chemical heterogeneity in a metallic undercooled liquid. Phys. Rev. B 95, 144210 (2017).

25. Widmer-Cooper, A. \& Harrowell, P. On the study of collective dynamics in supercooled liquids through the statistics of the isoconfigurational ensemble. $J$. Chem. Phys. 126, 154503 (2007).

26. Jakse, N. \& Pasturel, A. Transport properties and Stokes-Einstein relation in Al-rich liquid alloys. J. Chem. Phys. 144, 244502 (2016).

27. Trybula, M., Jakse, N., Gasior, W. \& Pasturel, A. Structural and physicochemical properties of liquid Al-Zn alloys: a combined study based on molecular dynamics simulations and the quasi-lattice theory. J. Chem. Phys. 141, 224504 (2014).

28. Jaiswal, A., Egami, T., Kelton, K. F., Schweizer, K. S. \& Zhang, Y. Correlation between fragility and the arrhenius crossover phenomenon in metallic, molecular, and network liquids. Phys. Rev. Lett. 117, 205701 (2016).

29. Jakse, N., Wax, J. F. \& Pasturel, A. Transport properties of liquid nickel near the melting point: an ab initio molecular dynamics study. J. Chem. Phys. 126, 234508 (2007)

30. Jakse, N. \& Pasturel, A. Dynamic properties and local order in liquid Al-Ni alloys. Appl. Phys. Lett. 105, 131905 (2014).

31. Pasturel, A. \& Jakse, N. On the role of entropy in determining transport properties in metallic melts. J. Phys. Condens. Matter 27, 325104 (2015).

32. Ding, J. \& Ma, E. Computational modeling sheds light on structural evolution in metallic glasses and supercooled liquids. Comput. Matter 3, 9 (2017).

33. Honeycutt, J. D. \& Andersen, H. C. Molecular dynamics study of melting and freezing of small Lennard-Jones clusters. J. Phys. Chem. 91, 4950-4963 (1987).

34. Hu, Y. C. et al. Five-fold symmetry as indicator of dynamic arrest in metallic glassforming liquids. Nat. Commun. 6, 8310 (2015).

35. Pasturel, A., Tasci, E. S., Sluiter, M. H. \& Jakse, N. Structural and dynamic evolution in liquid Au-Si eutectic alloy by ab initio molecular dynamics. Phys. Rev. B 81, R140202 (2010). 
36. Jakse, N. \& Pasturel, A. Local order of liquid and undercooled transition metal based systems: ab initio molecular dynamics study. Mod. Phys. Lett. 20, 655-674 (2006).

37. Maret, M., Pomme, T., Pasturel, A. \& Chieux, P. Structure of liquid $\mathrm{Al}_{80} \mathrm{Ni}_{20}$ alloy. Phys. Rev. B 42, 1598-1604 (1990).

38. Lad, K., Jakse, N. \& Pasturel, A. Signatures of fragile-to-strong transition in a binary metallic glass-forming liquid. J. Chem. Phys. 136, 104509 (2012).

39. Sheng, H. W., Luo, W. K., Alamgir, F. M., Bai, J. M. \& Ma, E. Atomic packing and short-to-medium-range order in metallic glasses. Nature 439, 419-425 (2006).

40. Kresse, G. \& Furthmüller, J. Efficiency of ab-initio total energy calculations for metals and semiconductors using a plane-wave basis set. Comput. Mater. Sci. 6, 15-50 (1996).

41. Ceperley, D. M. \& Alder, B. J. Ground state of the electron gas by a stochastic method. Phys. Rev. Lett. 45, 566-569 (1980).

42. Perdew, J. P. \& Zunger, A. Self-interaction correction to density-functional approximations for many-electron systems. Phys. Rev. B 23, 5048-5079 (1981).

43. Jakse, N. \& Pasturel, A. Liquid Aluminum: Atomic diffusion and viscosity from ab initio molecular dynamics. Sci. Rep. 3, 3135 (2013).

44. Binder K. \& Kob, W. Glassy Materials and Disordered Solids (World Scientific Publishing, 2005).
45. Alley, W. E. \& Alder, B. J. Generalized transport coefficients for hard spheres. Phys. Rev. A 27, 3158-3173 (1983).

46. Palmer, B. J. Transverse-current autocorrelation-function calculations of the shear viscosity for molecular liquids. Phys. Rev. E 49, 359-366 (1994).

Open Access This article is licensed under a Creative Commons Attribution 4.0 International License, which permits use, sharing, adaptation, distribution and reproduction in any medium or format, as long as you give appropriate credit to the original author(s) and the source, provide a link to the Creative Commons license, and indicate if changes were made. The images or other third party material in this article are included in the article's Creative Commons license, unless indicated otherwise in a credit line to the material. If material is not included in the article's Creative Commons license and your intended use is not permitted by statutory regulation or exceeds the permitted use, you will need to obtain permission directly from the copyright holder. To view a copy of this license, visit http://creativecommons. org/licenses/by/4.0/.

(c) The Author(s) 2017 